\title{
Dual-band doherty power amplifier with improved reactance compensation
}

\author{
Li M. Yu, Narendra K. Aridas, Tarik A. Latef
}

Department of Electrical Engineering, Faculty of Engineering, University of Malaya, Kuala Lumpur, Malaysia

\begin{tabular}{l}
\hline \hline Article Info \\
\hline Article history: \\
Received Jun 18, 2021 \\
Revised Jul 30, 2021 \\
Accepted Aug 1, 2021 \\
\hline
\end{tabular}

\section{Keywords:}

Doherty

Dual-band

Power amplifier

\begin{abstract}
In brief, a dual-band doherty power amplifier employing reactance compensation with gallium nitride high-electron-mobility transistor technology is discussed. This design is developed for long-term evolution (LTE) frequency operation, particularly for the application of two-way radio to improve the efficiency at the back-off point from saturation output power for selected dual frequencies in the LTE bandwidth. Measurements show that the prototype board has enhanced performance at the desired frequencies, namely a saturation output power of $40.5 \mathrm{dBm}$, and $6 \mathrm{~dB}$ back-off efficiencies of $43 \%$ and $47 \%$, which exhibit a gain of approximately $10 \mathrm{~dB}$ at $0.8 \mathrm{GHz}$ and $2.1 \mathrm{GHz}$, respectively.
\end{abstract}

This is an open access article under the CC BY-SA license.

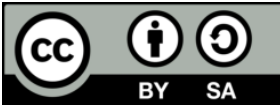

\section{Corresponding Author:}

Narendra K. Aridas

Department of Electrical Engineering

Faculty of Engineering

University of Malaya

50603 Kuala Lumpur, Malaysia

Email: narendra.k@um.edu.my

\section{INTRODUCTION}

To obtain decent output power from a power amplifier (PA), several techniques have been studied to improve the efficiency [1]-[8] and bandwidth [9]-[15]. In the past 20 years, doherty PAs (DPAs) have been studied considerably to enhance their bandwidth efficiency [16]-[19]. However, the majority of the published DPAs were designed to cater for single band but not multiband requirements. On the bright side, there have been several successful implementations of either dual-band PAs [20]-[22] or dual-band DPAs [23]-[25]. Zheng et al. [23] used simplified phase offset-lines to show that the dual-band DPA design can achieve efficiencies of $51.2 \%$ and $39.9 \%$ at the $6.5 \mathrm{~dB}$ back-off point from saturation power at frequencies of $0.90 \mathrm{GHz}$ and $2.14 \mathrm{GHz}$, respectively. Liu et al. [24] proposed a feasible dual-band DPA with a modified $\pi$-network to obtain drain efficiencies exceeding $49 \%$ and $47 \%$ at the $6 \mathrm{~dB}$ back-off point from saturated power across the frequency bandwidths of 2.05-2.30 GHz and 3.2-3.62 GHz, respectively. The dual-band DPA presented by [25] applied frequency-dependent input of power division and obtained power-added efficiencies of $45 \%$ and $41 \%$ at the 6 $\mathrm{dB}$ back-off point from saturation for frequencies of $0.85 \mathrm{GHz}$ and $2.33 \mathrm{GHz}$, respectively.

In the research on DPAs, especially dual-band DPAs, there are still rooms for improvement. The design of dual-band matching network to cater for two separate matching simultaneously is challenging and not easy to accomplish. As a matter of fact, the design involves higher complexity which resulted in the loss of performance, e.g., saturated efficiency and back-off saturated efficiency; a substantial degradation of the bandwidth in at least one of the intended frequency bands, which affects the frequency spacing of the dual-band. 
Herein, we introduce an improvement that enhances the dual-band back-off efficiency of the designed matching network for a DPA across a particular frequency bandwidth. The proposed design encompasses the dual-band frequencies of $0.8 \mathrm{GHz}$ and $2.1 \mathrm{GHz}$ as required in dual-band radio applications, and it is implemented in practice on a printed circuit board (PCB). The inductors are converted to distributed elements known as microstrips to improve the design by reducing the size to achieve small form factors. The presented prototype achieves decent $6 \mathrm{~dB}$ back-off efficiencies at both bands with little trade-off in saturated efficiency and supports wide frequency spacing between the dual-band. Moreover, the performance shows that the approach is acceptable for two-way radio communication applications. The remainder of the paper is arranged as follows. Section 2 shows the suggested dual-band DPA approach. The measurement findings and discussion are presented in Section 3, and the conclusion is presented in Section 4.

\section{DESIGN METHODOLOGY}

We present a novel approach in which we apply a mixed configuration of two different techniques namely the reactance compensation technique (RCT) and third-harmonic tuning in a DPA to improve the output matching network (OMN) for dual-band applications. Generally, the broadband matching network is designed by using the RCT. However, for dual-band DPA purposes, only the two specified bands need be enhanced; the unused bands must be attenuated to reduce the losses. Therefore, the RCT is improved to match the desired dual-band frequencies precisely. Figure 1, shows a design schematic for the RCT with a third-harmonic resonant circuit. For the output matching design, especially at the fundamental frequency for the carrier and peaking amplifier, the third-harmonic resonant circuit $\mathrm{L}_{\mathrm{t} 1} \mathrm{C}_{\mathrm{t} 1}$ and $\mathrm{L}_{\mathrm{t} 2} \mathrm{C}_{\mathrm{t} 2}$ are applied to ensure that the circuit is in the open-circuit condition. For this design, only the third harmonic is tuned, this has taken into consideration the factor in reducing the complexity of the matching network. Additionally, the presence of series $\mathrm{L}_{\mathrm{t} 1} \mathrm{C}_{\mathrm{t} 1}$ and $\mathrm{L}_{\mathrm{t} 2} \mathrm{C}_{\mathrm{t} 2}$ filters for the third-harmonic is effective for a narrow bandwidth, mainly only for an upper band of $2.1 \mathrm{GHz}$.

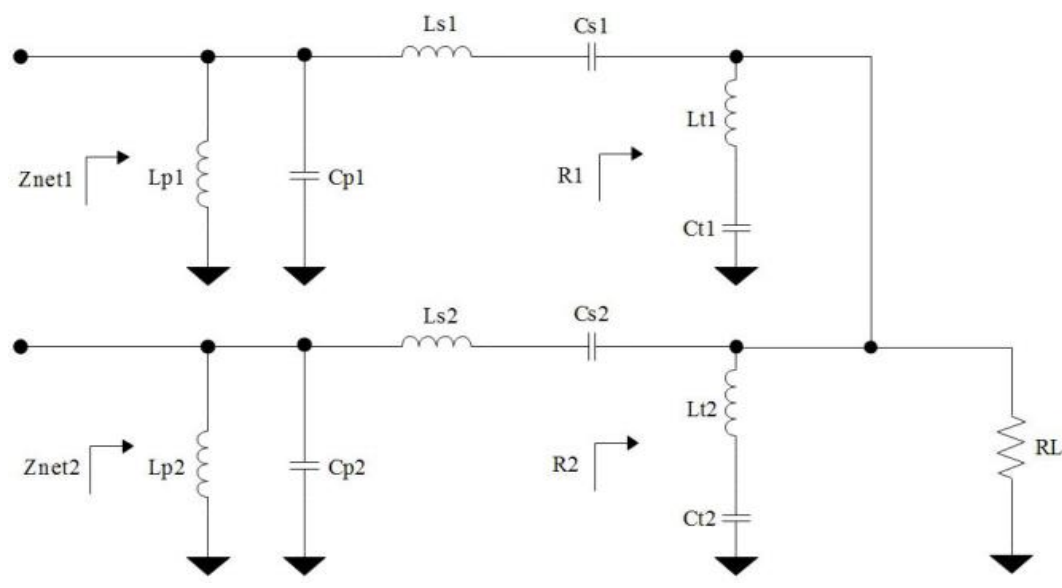

Figure 1. Reactance compensation technique (RCT) with third-harmonic resonant circuit

For the resonant circuits shown in Figure 2, both are connected to a load resistance $\mathrm{R}_{\mathrm{L}}$, which is tuned to match the fundamental frequency. Typically, the reactance for circuits in the series shunt configuration is affected by changes in the frequency. This can be explained by considering the situation in which the frequency rises and the reactance of the parallel resonant circuit is reduced. Moreover, this also increases the reactance of the series resonant circuit. Therefore, the compensation of the reactance near the selected dual resonant frequency is tuned predominantly to generate a constant load angle, and consequently developing a total variation of the reactance, which is equal to zero.

Furthermore, the value of the output impedance of the matching components introduced via this technique is tuned based on the optimal impedances obtained from the load-pull measurement to enhance the efficiency. With the aid of the advanced design system simulation software, the circuit is optimized to improve the dual-band matching requirement. The dual-band gallium nitride high-electron-mobility transistor (GaN HEMT) DPA is shown schematically in Figure 2 and comprises two 10 W CREE CGH40010F devices integrating with $\mathrm{V}_{\mathrm{dd}}=28 \mathrm{~V}$. For the input matching of the dual-band DPA, the lossy matching circuits of a shunt RL circuit and a series RC circuit are selected to provide minimal insertion loss for dual-band input 
matching. Based on Figure 2, (comprising a $12 \mathrm{pF}$ capacitor in parallel with a $10 \Omega$ resistor and in series with a $1000 \mathrm{pF}$ capacitor), the presence of the resistor on the input side of the matching network improves the stability of the network at lower frequencies.

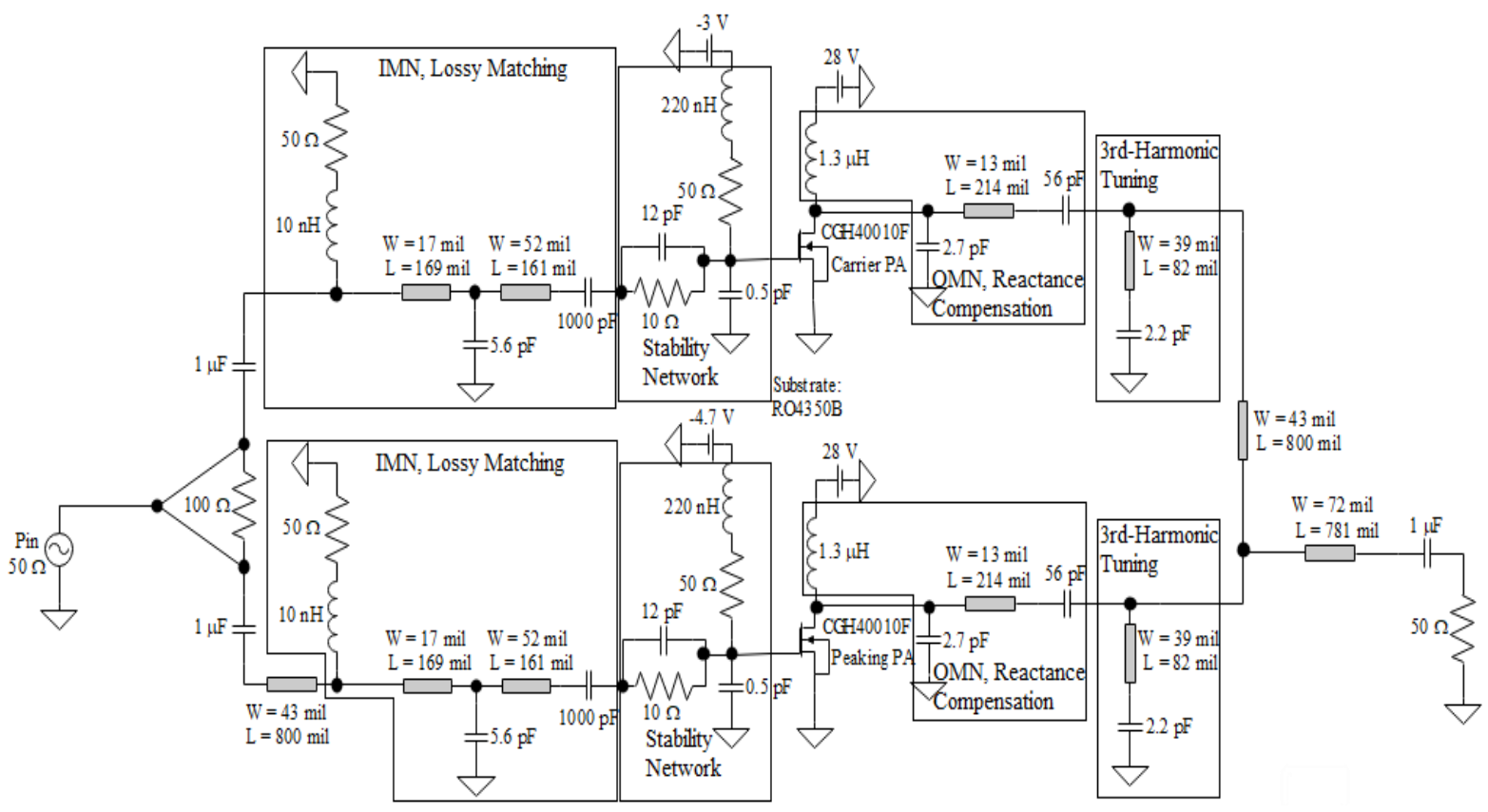

Figure 2. Simulated circuit schematic of dual-band gallium nitride high-electron-mobility transistor

(GaN HEMT) Doherty power amplifier (DPA)

The improvement in the power gain happens at higher frequencies when the resistor is circumvented. The RCT is applied to compensate individually for the reactance at the lower and upper bands. The OMN incorporated the RCT with the approach of optimizing the former to match two arbitrary complex impedances seen by the devices for two different frequencies of $0.8 \mathrm{GHz}$ and $2.1 \mathrm{GHz}$ to $50 \Omega$ load when the devices operate at $6 \mathrm{~dB}$ back-off from saturated power. Therefore, the load-pull of the output impedances is extracted at $6 \mathrm{~dB}$ back-off from the device saturation region. Table 1 gives the optimal output impedance obtained for each frequency. The concept of the third-harmonic resonant circuit is optimized and implemented together with the RCT at the OMN. Thus, decent tuning or optimization (with mixed lumped elements) is achievable throughout the matching networks.

Table 1. Optimal output impedances for dual-band DPA

\begin{tabular}{cc}
\hline Frequency $(\mathrm{GHz})$ & Optimal output impedance $(\Omega)$ \\
\hline 0.8 & $21.384+\mathrm{j} 17.354$ \\
2.1 & $61.330-\mathrm{j} 3.610$ \\
\hline
\end{tabular}

\section{MEASUREMENT RESULTS AND DISCUSSION}

To validate experimentally the results of the simulation for the proposed high-efficiency dual-band DPA, which incorporated the RCT and third-harmonic tuning, a prototype board was designed by integrating the CGH40010F GaN HEMT transistor from CREE. Figure 3, shows a photograph of the developed prototype board of the dual-band DPA. The board is connected to an external radio-frequency (RF) coaxial Wilkinson splitter (380-2500 MHz). The board has both input and output RF ports with matching networks and a four voltage supply feed for the gate and drain and the overall board dimensions are $125 \times 150 \mathrm{~mm}$. The matching networks are made up of lumped inductors that have been converted to microstrips. The implementation of this approach enhances the efficiency of fabricating the prototype, and the designed device's performance can be improved. The prototype is developed using a Rogers PCB, which has two layers; the substrate is $0.508 \mathrm{~mm}$ thick and the dielectric constant $\varepsilon_{r}$ is 3.66 . Nevertheless, an adequate area 
occupied by the dual-band DPA is much smaller at $73 \times 75 \mathrm{~mm}$. To provide a secure connection between the PCB and the heat sink, a total of eight screws are used to mount the PCB test board on the heat sink. Thus, to avoid board damage and to provide good heat dissipation, the solution is developed by reducing the heat from a high-power GaN HEMT, thereby maintaining good performance for longer. In particular, the voltage for the drain is set to $28 \mathrm{~V}$, while the current is adjusted to a quiescent state of $40-90 \mathrm{~mA}$ for both carrier PA and peaking PA. As for the gate, biases of $-3 \mathrm{~V}$ and $-4.7 \mathrm{~V}$ are applied for the carrier and peaking PAs, respectively. To minimize the coupling, the RF and direct-current (DC) signals are routed cautiously. For the DC routing, the width is chosen carefully to provide functional DC carrying capacity. The open grounding area for the board is well designed with isolation and an adequate number of via-holes. The latter are distributed evenly to enhance the grounding and to ensure decent performance of the dual-band DPA.

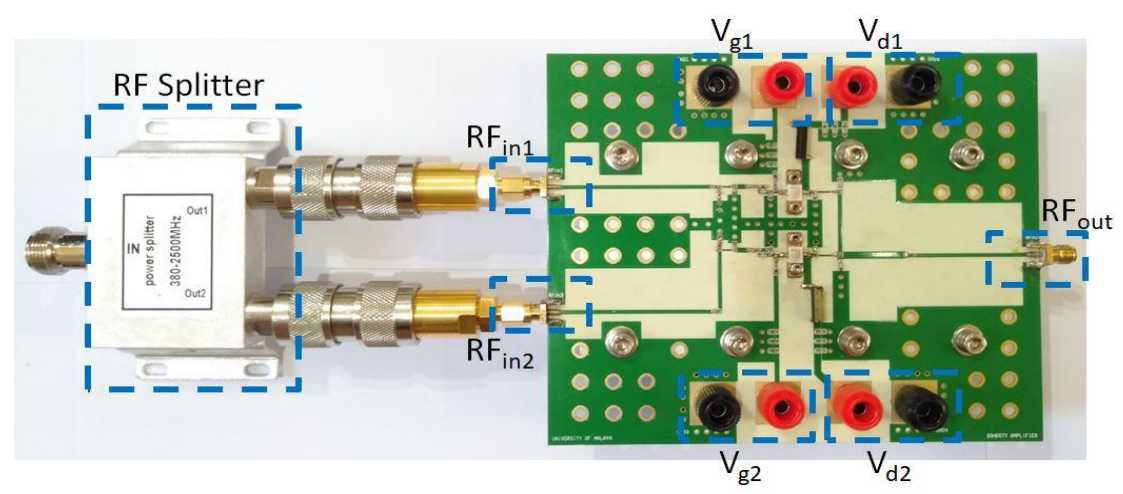

Figure 3. Actual prototype of dual-band DPA design board

Figure 4 and Figure 5, compare the simulated and measured performances of the proposed design. Figure 4, presents the simulation and measurement results for the gain and drain efficiency of the prototype board for $0.8 \mathrm{GHz}$ and $2.1 \mathrm{GHz}$, respectively. The measurements show efficiencies of $43 \%$ and $47 \%$ at 0.8 $\mathrm{GHz}$ and $2.1 \mathrm{GHz}$, respectively, for the $6 \mathrm{~dB}$ back-off point from saturation power. The gain measured is approximately $10 \mathrm{~dB}$ for $0.8 \mathrm{GHz}$ and $2.1 \mathrm{GHz}$, respectively. Specifically, the measured gains are $11.1 \mathrm{~dB}$ and $9.2 \mathrm{~dB}$ at $0.8 \mathrm{GHz}$ and $2.1 \mathrm{GHz}$, respectively.

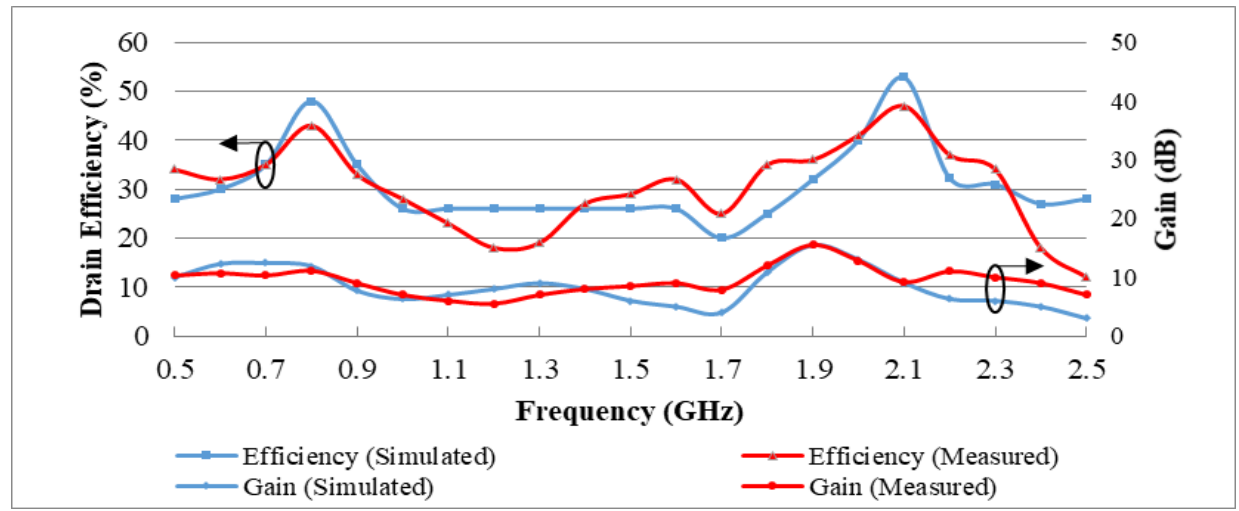

Figure 4. The gain and drain efficiency of the prototype board when simulated and measured at a $6 \mathrm{~dB}$ backoff from saturated power

This work has achieved a good result in simulation. However, there is a slight deviation between the measurements and the simulation results because the dual-band DPA was simulated under ideal conditions. This means that in a real-life experiment, the DPA's performance is affected by the non-ideal device characteristics. In fact, the variations in fabrication could also affect the performance of the prototype, and isolating the variability of the sources is challenging as it might be ascribed to the materials and equipment as well as due to the performance of humans in some circumstances. From the perspective of efficiency, the real 
transistor's knee region limits the available voltage swing, reducing the efficiency by approximately $10 \%$ compared to the ideal value at $0.8 \mathrm{GHz}$ and $2.1 \mathrm{GHz}$. Moreover, the changes in the conduction angle of the current relative to the power cause delays in turn-on of the Class-C biased peaking amplifier, resulting in a power loss at $6 \mathrm{~dB}$ back-off power from saturation. In a balanced power range mode, i.e., reactance compensation and third-harmonic resonant circuits are applied equally on the OMN of the carrier and peaking amplifier, both bands achieved characteristic impedances close to $50 \Omega$. Nevertheless, the operation power over the bandwidth is acceptable.

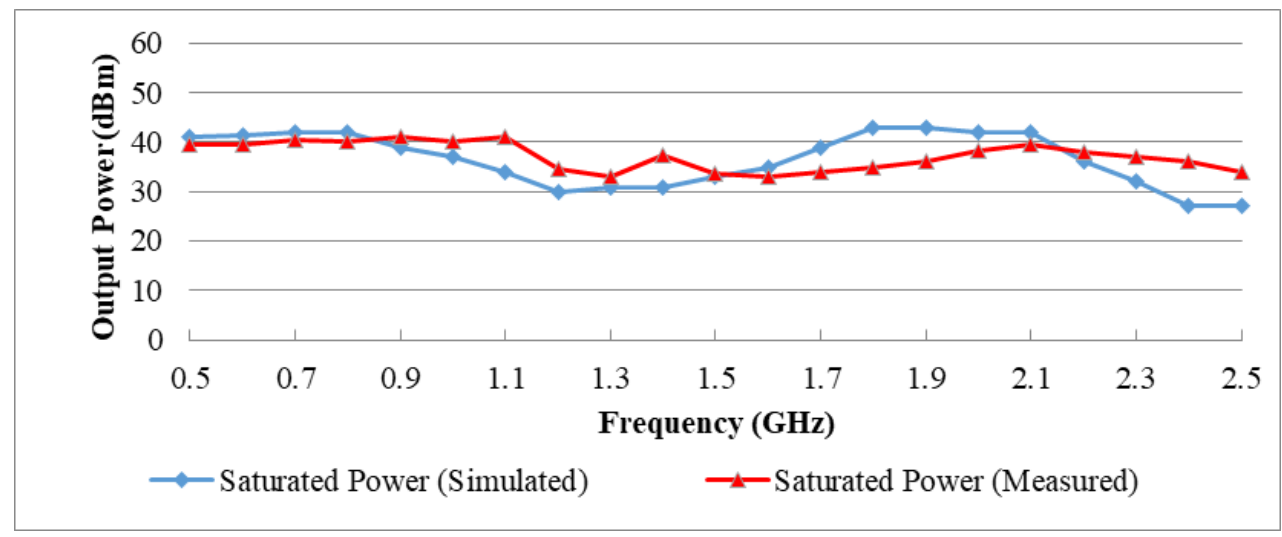

Figure. 5. Simulated and measured output power of prototype board

Figure 5, compares the output power between the simulation and the measurements in the frequency range of $0.5-2.5 \mathrm{GHz}$. For the desired frequency bandwidth, the saturation output power of $40.5 \mathrm{dBm}$ is attained. The measurements and the simulation results agree well and exhibit a decent dual-band performance. Table 2 compares recent studies of the performances of GaN dual-band DPAs.

Table 2. Comparison of performances of different dual-band DPAs

\begin{tabular}{|c|c|c|c|c|c|c|c|c|}
\hline \multirow[t]{2}{*}{ Work } & Topology & Device & $\begin{array}{l}\text { 'Frequency } \\
(\mathrm{GHz})\end{array}$ & $\begin{array}{l}\text { Frequency } \\
\text { Ratio (FR) }\end{array}$ & $\begin{array}{l}\text { Saturated } \\
\text { Efficiency } \\
(\%)\end{array}$ & $\begin{array}{l}\text { Efficiency } \\
(\%)\end{array}$ & $\begin{array}{l}\text { Saturated } \\
\text { Power } \\
(\mathrm{dBm})\end{array}$ & $\begin{array}{l}\text { Saturated } \\
\text { Gain }(\mathrm{dB})\end{array}$ \\
\hline & & & $\mathrm{f}_{1} / \mathrm{f}_{2}$ & $\mathrm{f}_{2} / \mathrm{f}_{1}$ & $\mathrm{f}_{1} / \mathrm{f}_{2}$ & $\mathrm{f}_{1} / \mathrm{f}_{2}$ & $\mathrm{f}_{1} / \mathrm{f}_{2}$ & $\mathrm{f}_{1} / \mathrm{f}_{2}$ \\
\hline [24] & $\begin{array}{l}\text { Modified П- } \\
\text { network }\end{array}$ & $\mathrm{GaN}$ & $2.15 / 3.4$ & 1.58 & $41.5 / 43.4$ & $\begin{array}{l}52 / 51 @ 6 \mathrm{~dB} \\
\mathrm{OBO}\end{array}$ & $47.3 / 47$ & $\begin{array}{l}7.5-9.5 / 9- \\
11\end{array}$ \\
\hline$[25]$ & $\begin{array}{l}\text { Frequency } \\
\text { dependent } \\
\text { input power } \\
\text { division }\end{array}$ & $\mathrm{GaN}$ & $0.85 / 2.33$ & 2.74 & $47.5 / 45$ & $\begin{array}{l}45 / 41 @ 6 \mathrm{~dB} \\
\mathrm{OBO}\end{array}$ & $44 / 42.5$ & $10 / 8$ \\
\hline $\begin{array}{l}\text { This } \\
\text { paper }\end{array}$ & $\begin{array}{l}\text { RCT + third- } \\
\text { harmonic } \\
\text { resonant } \\
\text { circuit }\end{array}$ & $\mathrm{GaN}$ & $0.80 / 2.10$ & 2.63 & $54 / 60$ & $\begin{array}{l}43 / 47 @ 6 \mathrm{~dB} \\
\text { OBO }\end{array}$ & $39.5 / 40.5$ & $10 / 10.2$ \\
\hline
\end{tabular}

Liu et al. [24] demonstrated high efficiency at $6 \mathrm{~dB}$ back-off from saturation for dual-band purposes. However, their frequency ratio (FR) was 1.58, which is considered narrow for frequency spacing. In the present study, an FR of 2.63 is attained to cater for the situation in which wide frequency spacing is required. Although the FR of the present study is not the highest, it is still comparable to [25] and fulfills the need for wide frequency spacing between dual-band. Interestingly, the present study obtained considerably higher saturation efficiency compared to other studies [24], [25], with $60 \%$ at $2.1 \mathrm{GHz}$ and maintaining a decent saturated efficiency of $54 \%$ at $0.8 \mathrm{GHz}$, while also showing comparable results to [23], particularly at higher frequencies. Moreover, the present study shows decent efficiency at $6 \mathrm{~dB}$ back-off from saturation without sacrificing the saturated efficiency. The gains are within the bandwidth of interest. 


\section{CONCLUSION}

Herein, a DPA employing the RCT with GaN HEMT technology for dual-band selection is discussed. The measurements show satisfactory achievement for obtaining efficiencies of $43 \%$ at $0.8 \mathrm{GHz}$ and $47 \%$ at $2.1 \mathrm{GHz}$ for a $6 \mathrm{~dB}$ back-off point from power saturation without much trade-off in saturated efficiency. The performance of the gain measured for the frequencies of $0.8 \mathrm{GHz}$ and $2.1 \mathrm{GHz}$ is approximately $10 \mathrm{~dB}$, which is considered to be a decent achievement. The prototype demonstrates $\sim 40 \mathrm{dBm}$ of output power at saturation for the desired frequency bandwidth. Therefore, the present approach is acceptable for two-way radio applications, particularly within the long-term evolution (LTE) frequency band.

\section{REFERENCES}

[1] W. H. Doherty, “A New High Efficiency Power Amplifier for Modulated Waves," Proc. Inst. Radio Eng., vol. 24, no. 9, pp. 1163-1182, Sep. 1936, doi: 10.1109/JRPROC.1936.228468.

[2] F. Wang, A.H. Yang, D.F. Kimball, L.E. Larson and P.M. Asbeck, "Design of wide-bandwidth envelope-tracking power amplifiers for OFDM applications," IEEE Trans. Microw. Theory Tech., vol. 53, no. 4, pp. 1244-1255, Apr. 2005, doi: 10.1109/TMTT.2005.845716.

[3] J. K. A. Everard and A. J. King, "Broadband power efficient Class E amplifiers with a non-linear CAD model of the active MOS device," J. Inst. Electron. Radio Eng., vol. 57, no. 2, pp. 52-58, Mar-Apr 1987, doi: 10.1049/JIERE.1987.0030.

[4] B. Sewiollo, G. Fischer, and R. Weigel., "A 12-GHz high-efficiency tapered traveling-wave power amplifier with novel power matched cascode gain cells using SiGe HBT transistors," IEEE Trans. Microw. Theory Techn., vol. 57, no. 10, pp. 2329-2336, Oct. 2009, doi: 10.1109/TMTT.2009.2029029.

[5] N. K. Aridas, C. Prakash, A. Grebennikov, and A. Mediano, "High-Efficiency Broadband Parallel-Circuit Class E RF Power Amplifier with Reactance-Compensation Technique," IEEE Trans. Microw. Theory Tech., vol. 56, no. 3, pp. 604-612, Mar. 2008, doi: 10.1109/TMTT.2008.916906.

[6] R. Krishnamoorthy, N. K. Aridas, A. Grebennikov, and H. Ramiah, "A High-Efficiency Ultra-Broadband MixedMode GaN HEMT Power Amplifier,” IEEE Trans. Circuits Syst. Express Briefs, vol. 65, no. 12, pp. 1929-1933, Dec. 2018, doi: 10.1109/TCSII.2018.2809491.

[7] C. R. Chappidi and K. Sengupta, "Globally Optimal Matching Networks With Lossy Passives and Efficiency Bounds," IEEE Trans. Circuits Syst. I Regul. Pap., vol. 65, no. 1, pp. 257-269, Jan. 2018, doi: 10.1109/TCSI.2017.2720179.

[8] N. K. Aridas, and T. Yewkok., "Optimised high-efficiency Class E Radio Frequency Power Amplifier for Wide Bandwidth and High Harmonics Suppression," IET Circuits Devices Syst., vol. 8, no. 2, pp. 82-89, Mar. 2014, doi: 10.1049/iet-cds.2013.0298.

[9] N. K. Aridas, B.S. Yarman, and P. Chacko, "Wideband power amplifier for two-way radio applications via realfrequency technique," Electron. Lett., vol. 50, no. 23, pp. 1762-1764, Nov. 2014, doi: 10.1049/el.2014.2972.

[10] Z. Dai, et al., "A New Distributed Parameter Broadband Matching Method for Power Amplifier via Real Frequency Technique," IEEE Trans. Microw. Theory Tech., vol. 63, no. 2, pp. 449-458, Feb. 2015, doi: 10.1109/TMTT.2014.2385087.

[11] B. S. Yarman, R. Kopru, N. K. Aridas, and C. Prakash., "High Precision Synthesis of a Richards Immittance Via Parametric Approach," IEEE Trans. Circuits Syst. I Regul. Pap., vol. 61, no. 4, pp. 1055-1067, Apr. 2014, doi: 10.1109/TCSI.2013.2285913.

[12] N. K. Aridas, H.Y. Huan, B.S. Yarman, and T.A. Latef, "Distributed power amplifier with novel integration technique of broadband impedance transformer using pseudomorphic HEMT and gallium nitride HEMT," IET Microwaves Antennas Propag., vol. 11, no. 7, pp. 949-954, Jun. 2017, doi: 10.1049/iet-map.2016.0934.

[13] A. Grebennikov, N. K. Aridas, and B.S. Yarman, Broadband RF and Microwave Amplifiers, $1^{\text {st }}$ ed., Florida: CRC Press, 2017.

[14] A. Grebennikov, N. O. Sokal, and M. J. Franco, Switchmode RF and Microwave Power Amplifiers, $2^{\text {nd }}$ ed., Oxford: Academic Press, 2012.

[15] R. Krishnamoorthy, N. K. Aridas, A. Grebennikov, B.S. Yarman, and H. Ramiah, "Broadband RF Power Amplifier with Combination of Large Signal X-Parameter and Real Frequency Techniques," IEICE Transactions on Electronics, vol. E103, no. 5, pp. 225-230, May. 2020, doi: 10.1587/transele.2019ECP5036.

[16] E. Bertran and M. Yahyavi, "A Wideband Doherty-Like Architecture Using a Klopfenstein Taper for Load Modulation," IEEE Microw. Wirel. Compon. Lett., vol. 25, no. 11, pp. 760-762, Nov. 2015, doi: 10.1109/LMWC.2015.2479847.

[17] C. H. Kim and B. Park, "Fully-Integrated Two-Stage GaN MMIC Doherty Power Amplifier for LTE Small Cells," IEEE Microw. Wirel. Compon. Lett., vol. 26, no. 11, pp. 918-920, Nov. 2016, doi: 10.1109/LMWC.2016.2615018.

[18] W. Jia, H. Yu, F. Yang, and D. Zhang, "A Broadband Doherty Amplifier With Back-Off Efficiency Enhancement," IEEE Microw. Wirel. Compon. Lett,. vol. 28, no. 8, pp. 723-725, Aug. 2018, doi: 10.1109/LMWC.2018.2842684.

[19] Y. Zhao, et al., "Doherty Transmitter Based on Monopole Array Antenna Active Load Modulation," IEEE Microw. Wirel. Compon. Lett., vol. 28, no. 10, pp. 927-929, Oct. 2018, doi: 10.1109/LMWC.2018.2863720.

[20] Pang, J., He, S., Huang, C., Dai, Z., Li, C., and Peng, J., "A Novel Design of Concurrent Dual-Band High Efficiency Power Amplifiers With Harmonic Control Circuits," IEEE Microwave Compon. Lett., vol. 26, no. 2, pp. 137-139, Feb. 2016, doi: 10.1109/LMWC.2016.2517334. 
[21] Y. Wu, L. Jiao, and Y. Liu, "Comments on 'Novel Dual-Band Matching Network for Effective Design of Concurrent Dual-Band Power Amplifiers'," IEEE Trans. Circuits Syst. I Regul. Pap., vol. 62, no. 9, pp. 2361-2363, Sep. 2015, doi: 10.1109/TCSI.2015.2459553.

[22] Z. Dai, S. He, J. Pang, and C. Huang, "Semi-analytic design method for dual-band power amplifiers," Electron. Lett., vol. 51, pp. 1336-1337, Aug. 2015, doi: 10.1049/EL.2015.0830.

[23] X. Zheng, Y. Liu, C. Yu, S. Li and J. Li, "Design of a Dual-Band Doherty Power Amplifier Utilizing Simplified Phase Offset-Lines," Progress In Electromagnetics Research C, vol. 48, pp. 21-28, Mar. 2014, doi: 10.2528/PIERC14012305.

[24] M. Liu, H. Golestaneh, and S. Boumaiza, "A concurrent 2.15/3.4 GHz dual-band Doherty power amplifier with extended fractional bandwidth," In 2016 IEEE MTT-S International Microwave Symposium (IMS), 2016, pp. 1-3, doi: 10.1109/MWSYM.2016.7540189.

[25] W. Chen, S. Zhang, Y. Liu, Y. Liu, and F.M. Ghannouchi, "A Concurrent Dual-Band Uneven Doherty Power Amplifier with Frequency-Dependent Input Power Division,” IEEE Trans. Circuits Syst. I Regul. Pap., vol. 61, no. 2, pp. 552-561, Feb. 2014, doi: 10.1109/TCSI.2013.2268341.

\section{BIOGRAPHIES OF AUTHORS}

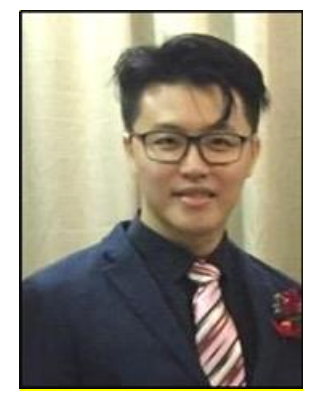

Li M. Yu graduated from the Universiti Malaysia Pahang in Malaysia with a B.Eng. Hons. degree in electrical and electronic engineering in 2014. He was a research assistant in Motorola Solutions Laboratory at the University of Malaya and currently doing his M.Eng.Sc. in the Department of Electrical Engineering, Faculty of Engineering, University of Malaya, Malaysia. His research areas of interest include high-efficiency power amplifier, embedded system, and massive multiple-input-multiple-output (MIMO).

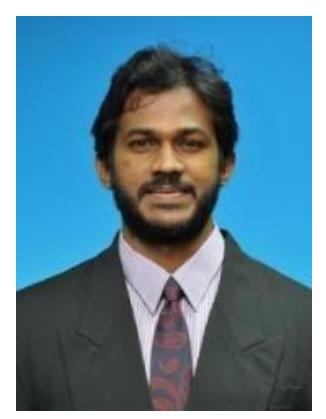

Narendra K. Aridas earned his Ph.D. in electrical engineering from Germany's RWTH Technical University Aachen. Since early 1999, he has worked with Motorola Solutions Research \& Development as a principal staff engineer (product architect).He owns seven patents (all assigned to Motorola Solutions) and has 15 years of expertise in applied electronics product development and testing. He is currently an Associate Professor at the Department of Electrical Engineering at the University of Malaya. He has published over 100 articles in technical journals and conferences, as well as three technical books in the field of Microwave \& RF in the United States of America. He has carried out few IEEE seminars related in Asia Pacific and Europe. He received the IEEE Microwave Propagation and System paper award in 2009, and his works on wideband matching circuits and nonlinear stability were invited to IEEE MMS 2010 (Cyprus) and IEEE WAMICON 2012 (Florida). He contributes to IET Circuit, System, Devices, and IEEE Transactions on Microwave Theory Techniques, and other journals as a reviewer. He is a Fellow of the IET (UK) and a Senior Member of the IEEE (USA). Since 2015, he has served as part of the IEEE Asia Pacific Industry Relations Team.

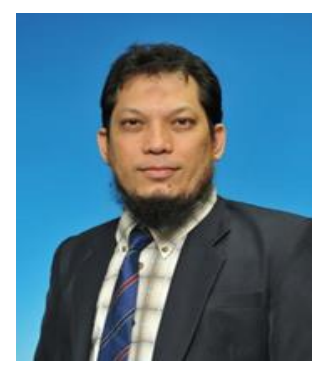

Tarik A. Latef graduated from the University of Oita in Japan with a B.Sc. degree in electrical and electronic engineering in 1997. In 2005 and 2011, he received his M.Sc. in electrical engineering from the University of Leeds and his Ph.D. from the University of Sheffield, both in the United Kingdom. He has been a Senior Lecturer at the University of Malaya's Faculty of Engineering's Department of Electrical Engineering since 2011. His areas of interest in research include superconducting matematerial antennas, dielectric resonator antennas, array design, frequency independence antennas, and conformal antennas. 